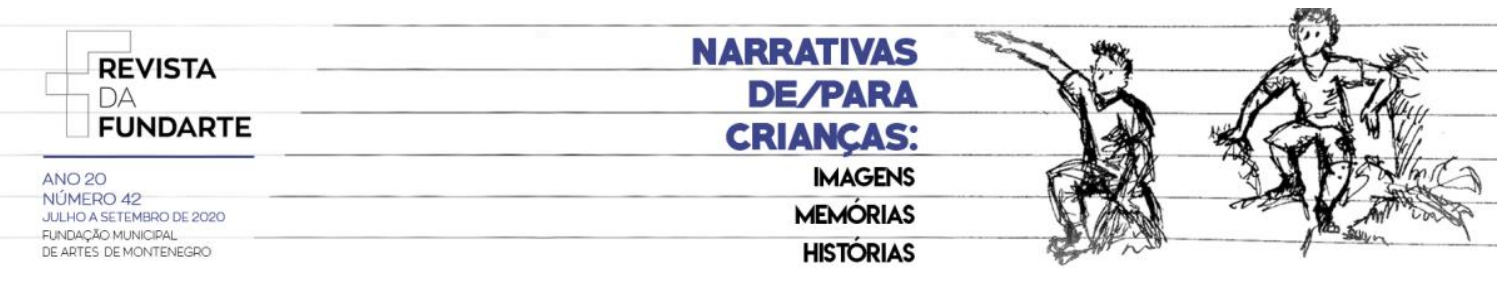

Gilka Girardello

DOI: 10.19179/2319-0868.791

GIRARDELLO, Gilka. Eu tenho uma coisa pra contar": Inspirações para a escuta das narrativas infantis. Revista da FUNDARTE. Montenegro, p.01-21, ano 20, no 42, julho/setembro de 2020.

Disponível em: http://.seer.fundarte.rs.gov.br/index.php/RevistadaFundarte/index> 30 de setembro de 2020 


\begin{tabular}{|l} 
REVISTA \\
DA \\
FUNDARTE
\end{tabular}

\title{
"EU TENHO UMA COISA PRA CONTAR": INSPIRAÇÕES PARA A ESCUTA DAS NARRATIVAS INFANTIS
}

Gilka Girardello ${ }^{1}$

\begin{abstract}
Resumo: $O$ artigo identifica e discute aspectos favoráveis à escuta adulta das histórias contadas oralmente pelas crianças, buscando contribuir para estimular a criação narrativa infantil. Sintetiza-se contribuições de pesquisas em diferentes campos das ciências humanas sobre a importância de as crianças contarem histórias para sua constituição subjetiva e cultural. Por meio de um diálogo com evidências empíricas de pesquisas brasileiras recentes no campo da Educação, destaca-se possíveis inspirações e estratégias para qualificar uma escuta respeitosa, atenta e dialógica das narrativas infantis.
\end{abstract}

Palavras-chave: Narrativa; Crianças; Escuta.

\section{"I HAVE A STORY TO TELL": INSPIRATIONS FOR LISTENING TO CHILDREN'S NARRATIVES}

\begin{abstract}
This article identifies and discusses factors that encourage adults to listen to stories told orally by children, to help stimulate narrative creation by children. It summarizes contributions from studies in different fields of the human sciences about the importance of children telling stories for their subjective and cultural formation. Through dialog with empiric evidence from recent Brazilian studies in the field of education, it highlights possible inspirations and strategies for qualifying respectful, attentive and dialogical listening to children's narratives.
\end{abstract}

Keywords: narrative, children, listening.

\section{« J'AI QUELQUE CHOSE À RACONTER » : DES SUGGESTIONS POUR INSPIRER L'ÉCOUTE DES RÉCITS D'ENFANTS}

Résumé: L'article identifie et examine des éléments qui favorisent l'écoute, de la part des adultes, des histoires racontées oralement par les enfants. II cherche à apporter une contribution à l'encouragement de la création narrative des enfants. II synthétise des recherches dans différents domaines des sciences humaines sur l'importance de raconter des histoires dans la formation subjective et culturelle des enfants. En dialoguant avec des données empiriques issues de recherches brésiliennes récentes dans le domaine de l'éducation, l'article met en lumière des suggestions et des stratégies possibles pour une écoute respectueuse, attentive et dialogique des récits d'enfants.

Mots-clés: Récit; Enfants; Écoute.

\footnotetext{
1 Professora Titular da Universidade Federal de Santa Catarina, vinculada ao Programa de PósGraduação em Educação. Realizou Doutorado em Ciências da Comunicação (Universidade de São Paulo), Mestrado Interdisciplinar em Ciências Sociais/Liberal Studies (New School for Social Research), e Graduação em Comunicação Social (UFRGS). Foi professora/pesquisadora visitante do Programa de Doutorado em Educação Urbana do Graduate Center/ City University of New York (Fulbright/Capes). Pesquisa as relações entre narrativa, infância, comunicação, cultura e arte.
}

GIRARDELLO, Gilka. Eu tenho uma coisa pra contar": Inspirações para a escuta das narrativas infantis. Revista da FUNDARTE. Montenegro, p.01-20, ano 20, no 42, julho/setembro de 2020.

Disponível em: http://.seer.fundarte.rs.gov.br/index.php/RevistadaFundarte/index> 30 de setembro de 2020 


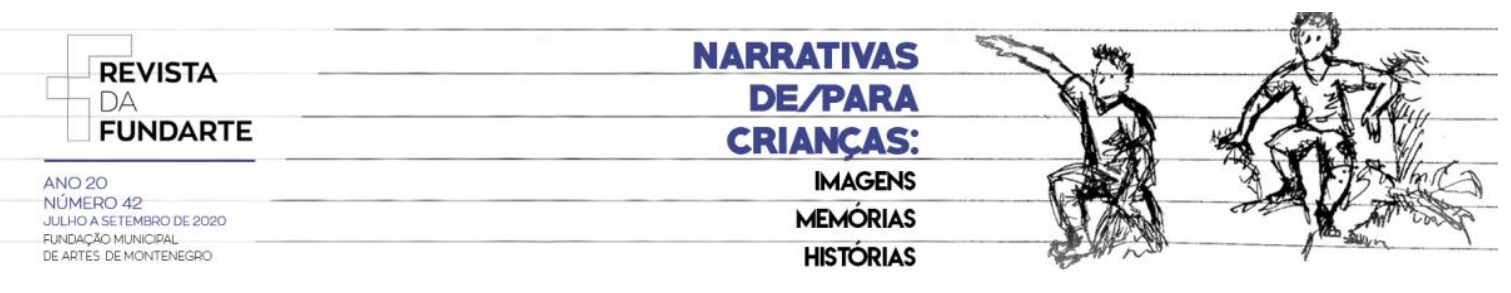

O que mais anima uma criança a contar suas histórias é saber que alguém está aberto a ouvi-la. Por isso, a proposta desse artigo é refletir, junto com outros(as) parceiros (as) de um mesmo caminho, sobre formas de tornar nossa escuta mais acolhedora, mais atenta e inspiradora à poética narrativa infantil, ou seja, a sua autoria no fiar das histórias.

Começo situando um contexto pessoal. Certa manhã, 25 anos atrás, acordei com uma cena imaginária muito viva na consciência: nela, crianças contavam histórias, sentadas em círculo no chão. Tinha ido dormir preocupada com a escolha da metodologia a ser usada na pesquisa de doutorado que estava começando a desenvolver. Aquela cena imaginária, que me chegou de presente do mundo dos sonhos, era a solução de que eu precisava. A partir daí, passei dois anos em uma pequena vila de pescadores, onde a televisão tinha chegado havia pouco tempo, escutando crianças me contarem suas histórias dentro de canoas ou em trapiches abandonados, tentando chegar mais perto de compreender seus processos imaginativos em meio à intensa mudança cultural que a comunidade vivia. Desde então, venho estudando a autoria narrativa infantil, suas lógicas e seus mistérios. $O$ objetivo deste trabalho, ao partilhar ideias e experiências que em anos mais recentes têm me parecido especialmente iluminadoras, é o de contribuir para ampliar a conversa entre os pesquisadores da infância sobre a preciosidade das histórias que as crianças contam em seu cotidiano e sobre as formas de ampliar os espaços e tempos para que essas histórias possam acontecer, com ênfase para a escuta adulta.

De início, seria bom lembrar alguns estudos seminais e noções preliminares sobre a importância das histórias na vida das crianças. O impulso para acompanhar uma história é um dos exercícios imaginativos mais importantes, desde muito cedo na vida das pessoas. O desejo de saber o que vem depois, que salvou a vida da hábil Sherazade, já pode ser percebido em crianças muito pequenas, por volta de um ano de idade, quando elas começam a se aventurar na linguagem. Muitos autores entendem que o ser humano, em suas ações e práticas, possa ser definido infantis. Revista da FUNDARTE. Montenegro, p.01-20, ano 20, no 42, julho/setembro de 2020.

Disponível em: http://.seer.fundarte.rs.gov.br/index.php/RevistadaFundarte/index> 30 de setembro de 2020 


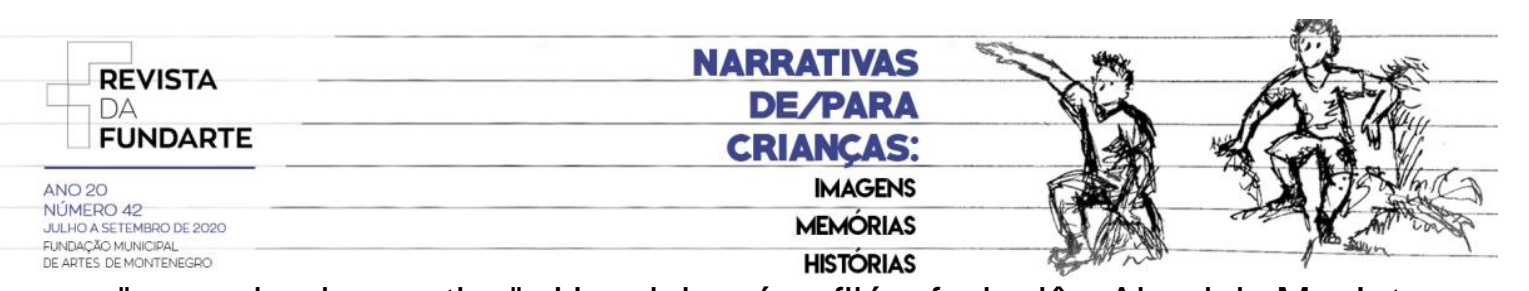

como "um animal narrativo". Um deles é o filósofo inglês Alasdair Maclntyre, para quem já chegamos ao mundo com um ou mais personagens e papéis atribuídos a nós, sendo que o único jeito de saber o que fazer a partir deles é recorrer ao estoque social de histórias:

\begin{abstract}
É ouvindo histórias sobre madrastas malvadas, crianças perdidas, reis bondosos mas desorientados, lobas amamentando gêmeos, filhos caçulas que não recebem herança e devem buscar a sorte no mundo, e filhos mais velhos que desperdiçam a herança e acabam vivendo no exílio, em meio aos porcos, que as crianças aprendem ou desaprendem o que é uma criança, o que é um pai ou uma mãe, o que o pode ser o conjunto de personagens entre os quais elas nasceram, e quais são os caminhos do mundo. Prive as crianças de histórias e você as deixará sem roteiro, gaguejando ansiosamente, tanto em suas ações como em suas palavras. (MACINTYRE, 1981, p. 201).
\end{abstract}

Na mesma direção, diz uma experiente arte-terapeuta inglesa: "As histórias contam a essência da experiência humana. Elas informam também sobre modos de resolver problemas e transcender dificuldades. Assim, um conto antigo não apenas mostra uma tradução de nossa experiência: ele também nos oferece um ou dois caminhos para nos movimentarmos dentro dela" (GERSIE, 1990, p. 19). Isto, pois "contar histórias não é apenas um jeito de dar prazer às crianças: é um modo de ampará-las em suas angústias, ajudá-las a nomear o que não podia ser dito, ampliar o espaço da fantasia e do pensamento" (KEHL, 2006, p.18). A forma narrativa é entendida assim como necessária à compreensão, ou mesmo como o modo básico de compreensão, algo que também propõe o psicólogo narrativista Jerome Bruner (1997). Fica reafirmada assim a importância radical de que nós, enquanto sociedades, culturas e indivíduos, prestemos muita atenção à qualidade, à quantidade e à diversidade das histórias que contamos às crianças de nosso tempo.

\title{
A voz narrativa das crianças
}

Quem escuta histórias aprende também a contá-las, completando o círculo de sentido em que, por meio da partilha narrativa, cria-se uma comunidade. $\mathrm{E}$ aproximamo-nos assim do foco mais específico deste trabalho, ou seja, a criação narrativa infantil e as formas de favorecê-la, especialmente nos modos de escutá-la.

GIRARDELLO, Gilka. Eu tenho uma coisa pra contar": Inspirações para a escuta das narrativas infantis. Revista da FUNDARTE. Montenegro, p.01-20, ano 20, no 42, julho/setembro de 2020.

Disponível em: http://.seer.fundarte.rs.gov.br/index.php/RevistadaFundarte/index> 30 de setembro de 2020 


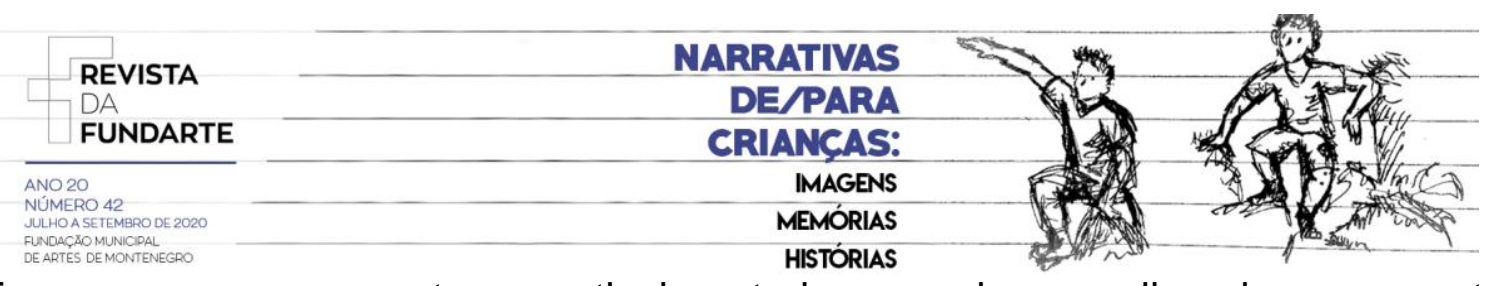

Temos como pressuposto, a partir de estudos que vimos realizando, que a autoria narrativa infantil possui dimensões éticas, estéticas e sobretudo lúdicas (GIRARDELLO, 2015, 2018).

Muitos estudos linguísticos e antropológicos mostram que as crianças são "inveteradas contadoras de histórias" (Sutton-Smith, 1981, p. 2), criadas a partir de suas experiências pessoais e dos padrões narrativos de sua cultura. Os conflitos com os quais a criança se depara vão sendo elaborados em termos dos padrões de resolução de enredo que a criança aprende com a cultura, observam Maranda e Maranda (apud Sutton-Smith, 1981, p.20), a narrativa é "um meio pelo qual as crianças adquirem a voz de sua cultura", confirmam Invernizzi e Abouzeid (1995, p.1). As crianças começam a desenvolver sua competência narrativa praticamente desde o berço, já que entre os 18 e os 20 meses de idade já são capazes de recontar o passado, organizando eventos em ordem cronológica (FIVUSH, 1991). $\mathrm{Na}$ perspectiva da psicanálise, Daniel Stern observa que "um sentido narrativo do eu" emerge a partir dos dois anos de idade, levando a criança a reorganizar a experiência subjetiva que tem dela mesma e de sua relação com os outros. (STERN, 1989). Como percebeu Maria Cecília Perroni, em pesquisa psicolinguística já clássica (1992), as crianças desenvolvem seu sentido narrativo ao conversar com os adultos, no que ela chama de "o jogo-do-contar": a criança fala "au-au", o adulto responde: "O au-au? O que ele fez? "; a criança completa: "au-au bóa"; o adulto joga de volta: "O au-au foi embora? ", e assim por diante. Assim começa, no diálogo com o outro, a entrega da criança ao voo imaginário, que com o tempo a levará a viver grandes aventuras no faz-de-conta, ouvindo e lendo histórias, brincando, assistindo, inventando, contando e encenando histórias, a bordo de caravelas, cavalos alados ou foguetes interplanetários.

A competência narrativa, enfim, cuja aquisição envolve enorme complexidade, é desenvolvida através da relação com os adultos, e na interação social de modo geral. Um exemplo citado por Vigotski evidencia o modo como a criança reelabora suas experiências, por meio da criação narrativa no diálogo com os adultos: "'O menino de três anos e meio ", conta Ribot, "ao ver um homem manco

GIRARDELLO, Gilka. Eu tenho uma coisa pra contar": Inspirações para a escuta das narrativas infantis. Revista da FUNDARTE. Montenegro, p.01-20, ano 20, № 42, julho/setembro de 2020.

Disponível em: http://.seer.fundarte.rs.gov.br/index.php/RevistadaFundarte/index> 30 de setembro de 2020 


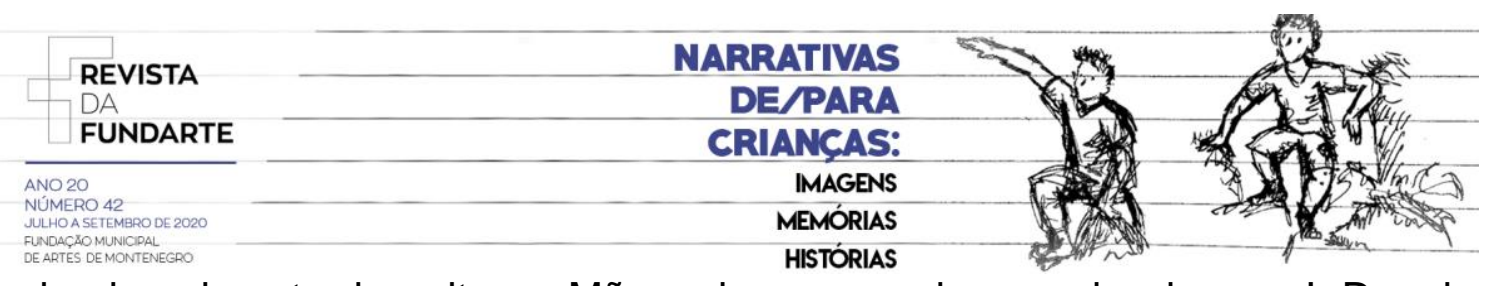

andando pela estrada, gritou: - Mãe, veja a perna desse pobre homem!. Depois, ele começou a contar uma história: o homem estava sentado num cavalo alto, caiu por cima de uma pedra grande, machucou a perna; é preciso encontrar algum pozinho para curá-lo'" (VIGOTSKI, 2010, p.17). Como mostra esse exemplo, pela narrativa a criança exerce a atividade combinatória de sua imaginação, construindo algo novo que faz sentido para ela, a partir do que vê.

Os relatos de experiência pessoal são considerados um importante espaço de construção social do eu. $\mathrm{Na}$ "participação rotineira em práticas narrativas organizadas culturalmente nas quais são contadas experiências pessoais" as crianças "desenvolvem meios de expressar e entender quem elas são" (MILLER et al, 1990, p. 295). É também na conversa sobre experiência pessoal com os adultos que as crianças aprendem a atribuir cronicidade às narrativas, a falar sobre 0 passado, e mesmo a pensar sobre o passado (SUTTON-SMITH, 1991; FIVUSH, 1991). Além de todos esses importantes efeitos, o acesso às histórias pessoais narradas por adultos tem um papel intimamente ligado à imaginação: a romancista Eudora Welty disse certa vez que seu sentido dramático - a noção de que tudo acontece em cenas - surgiu dos relatos de experiência pessoal entreouvidos quando era criança (MILLER; MELLER, 1994). Os temas das histórias são em geral os mesmos temas presentes nas brincadeiras e nos desenhos produzidos pelas crianças a cada período, observa Sutton-Smith, mas "é improvável que as crianças contassem histórias sem o exemplo dos que a rodeiam" (1991, p. 131). E o grau de encorajamento e de atenção dado pelos adultos à narração das crianças depende de variáveis culturais, já que embora a narrativa seja uma atividade cultural universal (TURNER, 1981), os tipos de histórias e conteúdos que se costuma contar variam de uma cultura para outra, e mesmo dentro de uma única sociedade (BERMAN, 1995).

Outro importante espaço de prática narrativa são os grupos de crianças, em que são contados relatos de experiência, piadas, brincadeiras. Um dos gêneros frequentemente exercitados em grupo, é a partilha oral de fantasias, entendendo-se fantasia aqui como "a interpretação criativa, imaginada e partilhada de eventos que

GIRARDELLO, Gilka. Eu tenho uma coisa pra contar": Inspirações para a escuta das narrativas infantis. Revista da FUNDARTE. Montenegro, p.01-20, ano 20, № 42, julho/setembro de 2020.

Disponível em: http://.seer.fundarte.rs.gov.br/index.php/RevistadaFundarte/index> 30 de setembro de 2020 


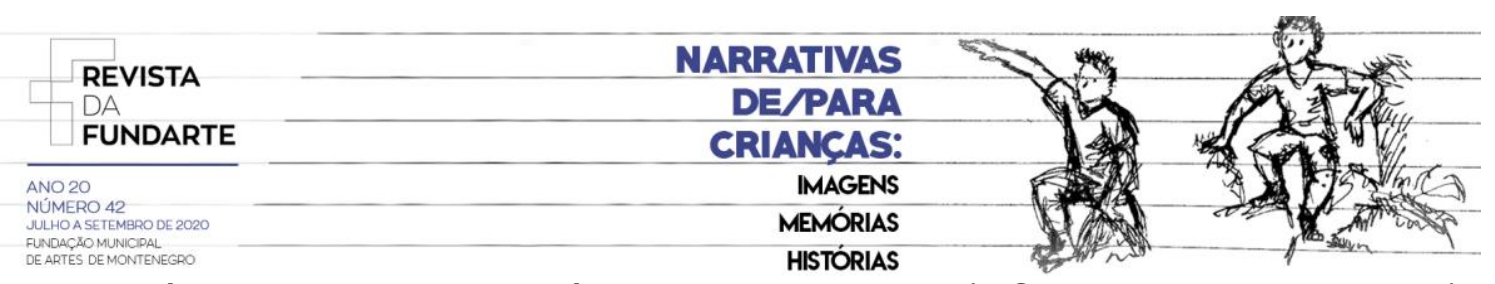

atendam à necessidade psicológica de um grupo" (BORMANN, 1986, p.128). Em tais grupos as crianças recriam a cultura adulta, mais do que a reproduzem. Especialmente iluminador nesse sentido é o trabalho de William Corsaro sobre a socialização infantil, no qual ele define a cultura dos grupos de crianças (cultura de pares) como um conjunto "de atividades ou rotinas, artefatos, valores e preocupações que as crianças produzem e compartilham." (CORSARO, 2011, p. 128)

A possibilidade de as crianças brincarem livremente sem supervisão adulta faz com que elas tenham um espaço próprio de criação cultural. Essa questão foi examinada por Edmir Perrotti, que critica a perda do espaço para a brincadeira infantil ocorrida no Brasil com a urbanização, e a tentativa de sua substituição por produtos culturais realizados por adultos. Ele cita a pesquisa feita por Florestan Fernandes acerca dos grupos infantis no bairro paulista do Bom Retiro. Nessa pesquisa, feita em 1941 e 1942, o sociólogo constatou que as crianças adquirem em interação "uma cultura infantil, cujo suporte social consiste nos grupos infantis" (FERNANDES, 1979), e a existência, segundo Perrotti, de

uma cultura própria, viva, transmitida boca-a-boca e que, embora muitas vezes busque seus elementos na outra mais genérica, organizada pelos adultos, ainda assim é reelaborada, segundo suas necessidades, pelos grupos infantis que os transformam em algo próprio e diverso daquilo que Ihes serviu de inspiração. (1990, p. 22).

Assim, sob condições favoráveis, a cultura dos grupos de crianças é uma produção coletiva, na qual crianças se apropriam da cultura adulta e a transformam. A narração é um dos meios pelos quais essa recriação se dá, já que introduz no grupo temas e gêneros aprendidos com os adultos, porém filtrados pela perspectiva subjetiva das crianças, ou seja, reimaginados, e em permanente processo de reimaginação. Nos tempos que correm, entre tanta cacofonia, alarido, repetição reativa e desatenta, em que um verbo tão valioso como "compartilhar" virou sinônimo de repassar mensagens sem muitas vezes ouvi-las ou lê-las direito, parece especialmente importante o alerta de Richard Kearney (1988), sobre a necessidade

GIRARDELLO, Gilka. Eu tenho uma coisa pra contar": Inspirações para a escuta das narrativas infantis. Revista da FUNDARTE. Montenegro, p.01-20, ano 20, № 42, julho/setembro de 2020.

Disponível em: http://.seer.fundarte.rs.gov.br/index.php/RevistadaFundarte/index> 30 de setembro de 2020 


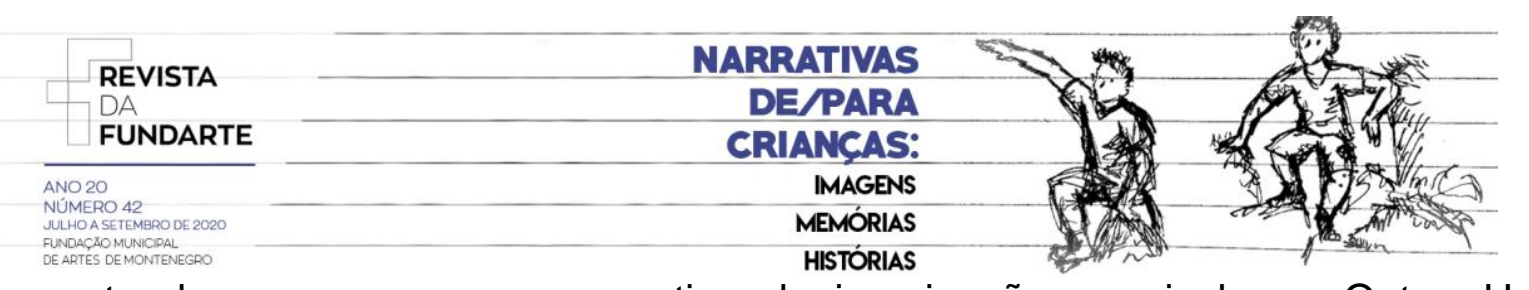

urgente de que recuperemos um tipo de imaginação que inclua o Outro. Uma imaginação que, na bela imagem de Maxine Greene (1995, p. 38), signifique "tornarse amigo da mente de outra pessoa".

Traduzindo essa preocupação para o universo da cultura infantil, apontamos a necessidade da criação imaginativa coletiva, em que as crianças se apropriem das histórias e formas artísticas, tanto aquelas que vêm de longe, quanto as produzidas pelas pessoas que vivem a seu redor. Quanto mais diverso for o repertório que recebem da cultura e com o qual brincarão, menor tenderá a ser o risco de empobrecimento cultural, temido por tantos autores.

$\mathrm{Na}$ pesquisa a qual me referi no início, realizada na comunidade da Costa da Lagoa, desde o primeiro dia as crianças mencionaram as "coisas que outras pessoas contaram" como uma categoria narrativa possível. E deram exemplos, nos quais as crianças que narram colocam-se como elos na cadeia de transmissão oral em que, segundo Lyotard (1990), a condição de contar é dada pela condição de ter ouvido um dia. Do mesmo modo como a criança aprende a narrar escutando histórias, ela aprende que para narrar é preciso também receber a escuta do outro, uma escuta que ela conhece por experiência própria por ter aprendido a ouvir. Como fazem os adultos no pacto da narração oral vigente, as crianças iniciam cada relato informando de quem ouviram o que vão contar:

O meu avô me contou que quando ele era moço ele ia pescar. Aí vinha os outros e lá atrás de uma bananeira ouvia um machado batendo na bananeira. Os outros iam embora correndo e ele ficava. Daí chegou um dia que ele foi lá ver o que era: era o Bastiano ${ }^{2}$ que batia com o machado pra espantar todos pra ficar pescando sozinho (Daniela, 9 anos).

Se eu falar tudo que a minha avó conta, não vai dar hoje. Ela gosta de contar historinha assim do...tempo...quando ela vivia quando eu não tava. (...)Ela fica fazendo renda e fica conversando com os filhos dela, com os neto. Uma vez ela contou que eles iam fazer farinha, e a vaca não quis andar. $A$ vaca deu um coice, e ela foi longe. (Martina, 10 anos)

A minha história é do meu vô, pode? É que um dia o meu vô disse que um amigo do meu vô disse que ele tinha um terreno no céu. Toda noite que eu ia lá o vô dizia isso pra mim, aí eu não acreditava. Aí uma vez o amigo do vô foi lá, aí eu perguntei, e ele disse assim: "É verdade!". Aí eu disse

2 Os nomes das crianças e das pessoas mencionadas nas narrativas foram alterados.

GIRARDELLO, Gilka. Eu tenho uma coisa pra contar": Inspirações para a escuta das narrativas infantis. Revista da FUNDARTE. Montenegro, p.01-20, ano 20, no 42, julho/setembro de 2020.

Disponível em: http://.seer.fundarte.rs.gov.br/index.php/RevistadaFundarte/index> 30 de setembro de 2020 


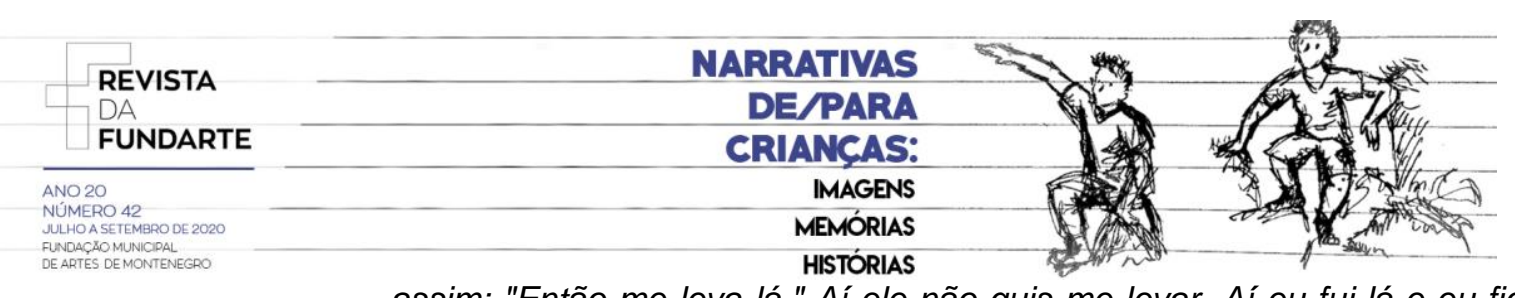

assim: "Então me leva lá." Aí ele não quis me levar. Aí eu fui lá e eu fiquei zangado com ele. Um dia ele passou no caminho ali de casa e eu joguei uma pedra nele. Pegou no ombro, aí ele brigou comigo. Eu tinha uns cinco anos, parece...Eu imaginava que o terreno no céu era bonito e ele não quis me levar... Hoje eu penso que era mentira (Wilson, 11 anos).

Todos os relatos acima e muitos outros dos que ouvi baseiam-se em narrativas pessoais de adultos, confirmando o papel central dessa forma narrativa na experiência oral das crianças. Pode acontecer, porém, que os(as) narradores(as) a seu lado se calem, sintam arrefecer seu ímpeto diante das mudanças vertiginosas do mundo, ou sejam simplesmente paralisados(as) pelas pressões sociais, econômicas e culturais. Nesse caso, se rarefaz a mediação adulta que é tão importante para a imaginação infantil, e a experiência cultural da criança se desequilibra, dada a predominância dos critérios do mercado na oferta das histórias ao público infantil, via TV e internet. O contexto mais favorável para evitar esse desequilíbrio seria aquele em que as crianças pudessem ouvir os adultos, ouvir umas às outras e ouvir a si mesmas contando histórias, viessem elas da experiência ou da ficção, da literatura ou dos meios audiovisuais. Ao contar e ao ouvir contar, as crianças mergulham na inteligência narrativa de que fala Paul Ricoeur (1995): seguem suas ondas e ritmos, exercem-na.

Assim, as crianças precisam, de um lado, ter acesso à riqueza narrativa; de outro, receber a escuta atenta, curiosa e solidária de quem está ao lado delas, para que desenvolvam a confiança em sua própria voz de narradoras. "O que é preciso para que uma criança conte uma história?"- pergunta Luciana Hartmann - "Penso que o fundamental nessa resposta é: alguém que a escute - o que inclui ouvintes tão diversos quanto: outras crianças, adultos, animais de estimação ou mesmo seus bonecos preferidos" (HARTMANN, 2015, p. 48). A escuta às crianças é um dos eixos teórico-metodológicos do campo interdisciplinar dos Estudos da Infância, especialmente no caso das pesquisas com crianças, onde ouvir é "captar e procurar entender; escutar o que foi dito e o não dito; valorizar a narrativa, entender a história" (SILVA; BARBOSA; KRAMER, 2008, p. 86).

GIRARDELLO, Gilka. Eu tenho uma coisa pra contar": Inspirações para a escuta das narrativas infantis. Revista da FUNDARTE. Montenegro, p.01-20, ano 20, no 42, julho/setembro de 2020.

Disponível em: http://.seer.fundarte.rs.gov.br/index.php/RevistadaFundarte/index> 30 de setembro de 2020 


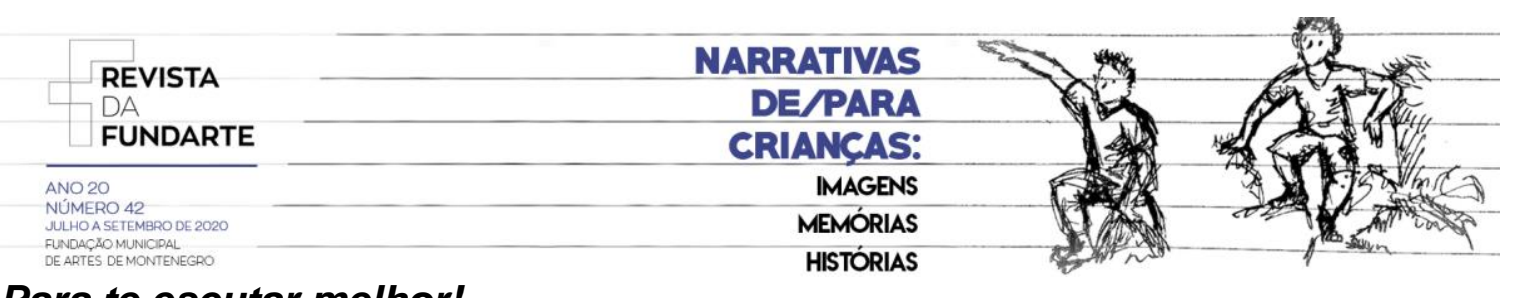

\section{Para te escutar melhor!}

Quem conta histórias "bebe-as dos olhos de quem as escuta", como diz o narrador paulista Giba Pedrosa. Qualquer pessoa que já contou uma história sabe da importância da escuta atenta e cúmplice de quem ouve, para que a narração flua bem. Contar histórias é um ato de diálogo, que se dá no encontro fugaz e singular entre narrador e ouvinte, mediados pelo conto. Uma escuta solidária não significa necessariamente uma escuta silenciosa. Ela pode envolver perguntas e comentários, se seguirmos a ideia de compreensão responsiva de Bakhtin, que dizia que "ser ouvido já é uma relação dialógica" (Bakhtin, 1986, p. 127). É por isso que costumamos recorrer à ideia de uma "clareira imaginária" para falar do espaço simbólico de uma partilha narrativa em performance. Trata-se de uma troca de presentes: te dou minha voz, minha palavra, e me dás tua escuta, para que nossas imaginações possam dançar juntas.

Escutar uma criança pede calma, pede a entrega ao sabor da música tão especial com que as crianças tateiam o sentido, valendo-se das palavras e recursos de linguagem que conhecem. É não querer que ela "diga logo" alguma coisa. É respeitar seus silêncios, ritmos e hesitações. Escutar uma criança é colocar todos os nossos recursos sensíveis - não só a audição e o pensamento, mas também o olhar, a respiração, os gestos, a postura corporal - a serviço da acolhida ao que ela quer dizer, ainda que não o saiba. (Sim, pois o narrar é também um espaço de ensaio, um espaço precioso para elaborar sensações, intuições e experiências, dando a elas um sentido que ainda não existia quando se começou a falar.) Escutar uma criança é refrear o impulso ao julgamento, modular com sensibilidade a crítica e evitar reações automáticas ou previsíveis ao que elas nos contam. Cada história é única, assim como são únicos os narradores, cobrando de quem escuta posturas também únicas para que as crianças percebam ali a cumplicidade de uma rede de segurança forte e flexível onde possam se atirar sem medo. E não é por sermos adultos que teremos sempre a obrigação de responder à história da criança com um ensinamento ou conselho "sábio". Às vezes, as crianças compartilham conosco

GIRARDELLO, Gilka. Eu tenho uma coisa pra contar": Inspirações para a escuta das narrativas infantis. Revista da FUNDARTE. Montenegro, p.01-20, ano 20, № 42, julho/setembro de 2020.

Disponível em: http://.seer.fundarte.rs.gov.br/index.php/RevistadaFundarte/index $>30$ de setembro de 2020 


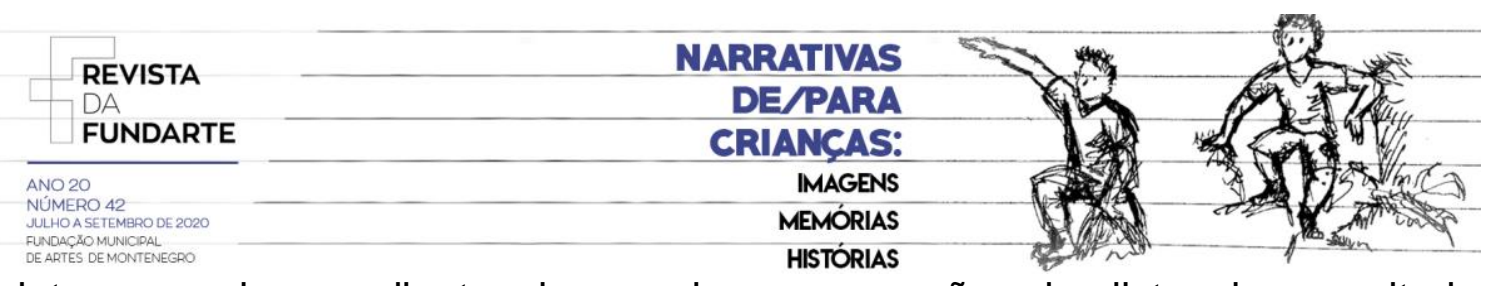

relatos complexos, diante dos quais uma reação simplista desrespeitaria os mistérios e as dificuldades que a criança neles conseguiu formular.

Sobre as possíveis reações que cada história desperta ao seu final, é interessante o que diz Elizabeth Ellis (1997). Segundo ela, algumas narrativas provocam no ouvinte uma risada; outras, um "Ahá!" diante de "uma virada surpreendente, uma situação de lógica ou engenhosidade que encanta os ouvintes e os encoraja a se envolver ativamente". Outras, no entanto, e é isto o que quero destacar, "levam os ouvintes às selvas escuras e às profundas cavernas da experiência humana", uma viagem da qual eles precisam ser gentilmente acordados para que possam reentrar no mundo cotidiano. Reconhecer que as histórias das crianças também podem ter esse poder sobre nós é um pressuposto da escuta compreensiva. Várias vezes nos vemos sem palavras diante de algum relato de experiências das crianças. Isso me aconteceu, por exemplo, uma tarde, na pesquisa na Costa da Lagoa, quando uma menina contou que tinha enterrado com orações um passarinho morto pelo irmão; duas outras meninas contaram funerais de passarinho de que tinham participado. A primeira menina, Rosalice (12 anos), arrematou a conversa com a seguinte reflexão contra os matadores de passarinho: "Eles são assim, ó, eles não gostam de ver ela assim, dançando. (Apontou para uma extrovertida colega.) Eles já ficam com raiva. Faz de conta que ela é um passarinho. Se ela tá dançando ali, é a mesma coisa. O passarinho, ele não dança, ele canta! ". Meu papel nesses casos foi o de apenas acolher e reconhecer a importância de tais colocações - até porque eu nada saberia acrescentar a sua profundidade.

Se no caso acima fiquei sem palavras diante da narrativa da criança, no diálogo a seguir a pesquisadora Karin Campos soube o que dizer a uma menina narradora, em uma oficina de histórias. A pesquisadora tinha sugerido, em um encontro anterior, que as crianças trouxessem alguma coisa que para elas "valesse ouro", (inspirada na leitura do livro de Mem Fox "Guilherme Augusto Araújo Fernandes"), como forma de suscitar a narração de histórias pessoais.

GIRARDELLO, Gilka. Eu tenho uma coisa pra contar": Inspirações para a escuta das narrativas infantis. Revista da FUNDARTE. Montenegro, p.01-20, ano 20, no 42, julho/setembro de 2020.

Disponível em: http://.seer.fundarte.rs.gov.br/index.php/RevistadaFundarte/index> 30 de setembro de 2020 


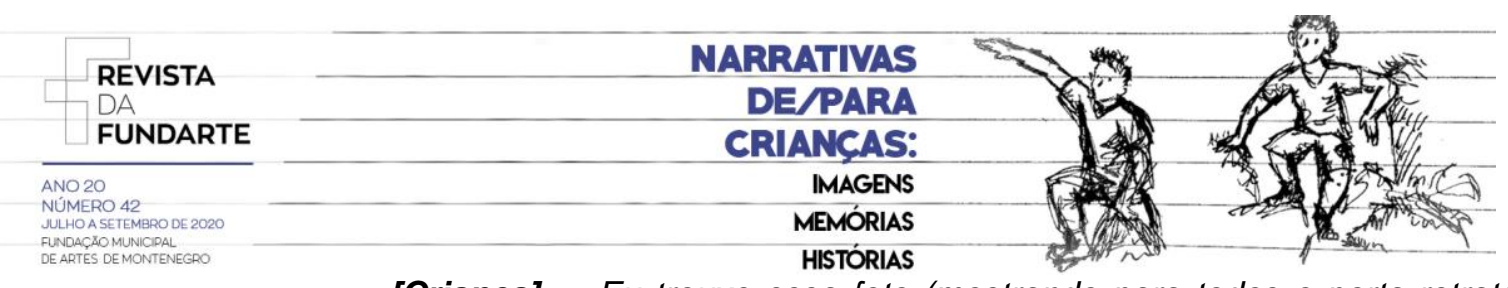

[Criança]: - Eu trouxe essa foto (mostrando para todos o porta-retrato na roda) que pra mim vale ouro, porque é a foto da minha família. Daí, era meu pai, meu irmão, minha mãe, eu tava aqui nessa barriguinha aqui, ó (apontando a barriga da mãe grávida na foto). E pra mim vale ouro porque é a foto da minha família (olhos emocionados e brilhantes).

Pesquisadora: - Há outra coisa que você também havia pensado em trazer?

[Criança]: - Trazer a minha mãe aqui na escola. Mas ela não podia vir porque ela tem que fazer um monte de serviço em casa.

Pesquisadora: - Mas de alguma forma você a trouxe, no retrato. (Campos, 2016, p. 85).

Para que a narrativa da criança flua livre e de uma fonte profunda é preciso tempo, pois "as horas param para que dentro da história cada um que conta ou escuta possa brincar", como diz Regina Machado (2002, p. 49). O lugar do adulto, com suas responsabilidades pragmáticas pelas crianças, muitas vezes não é propício a essa entrega, a um escutar que é deriva, que é mais água de mangue a borbulhar, ou igarapé a se espalhar, do que rio que corre entre margens estáveis de sentido. Assim, às vezes escutamos as crianças contando seus casos e temos dificuldade de apenas escutá-las, sem avaliar, analisar, logo pensando no que vamos responder, ou quais ações nossas aquela fala da criança tenderá a deflagrar a seguir. O valor da escuta atenta às histórias das crianças é defendido assim por Susan Engel:

\begin{abstract}
Quando as crianças sabem que alguém as está escutando com interesse, elas se sentem bem, motivam-se a continuar, ganham coragem para se expressar. (...) [Escute cada criança] tendo como ponto de partida que ela é uma parceira de conversa interessante, complexa e valiosa, e que suas histórias possuem tantas riquezas quanto as de qualquer outra pessoa da comunidade. (ENGEL, 2000, p. 210).
\end{abstract}

Quando falamos na clareira imaginária de sentido comum que se abre quando contamos histórias às crianças, é porque podemos apostar na entrega com que elas se dispõem a imaginar cada cena narrada. Porque nas crianças o estado de presença reina mais plenamente do que no corre-corre do cotidiano adulto, antes que esse retorne ao estado de presença que encontramos também nos mais velhos. Sobre isso, é muito inspirador um conto escutado por A.K. Ramanujan entre o povo telugu, no sul da Índia. É o caso de uma velha senhora que, para cumprir um ritual

GIRARDELLO, Gilka. Eu tenho uma coisa pra contar": Inspirações para a escuta das narrativas infantis. Revista da FUNDARTE. Montenegro, p.01-20, ano 20, no 42, julho/setembro de 2020.

Disponível em: http://.seer.fundarte.rs.gov.br/index.php/RevistadaFundarte/index $>30$ de setembro de 2020 


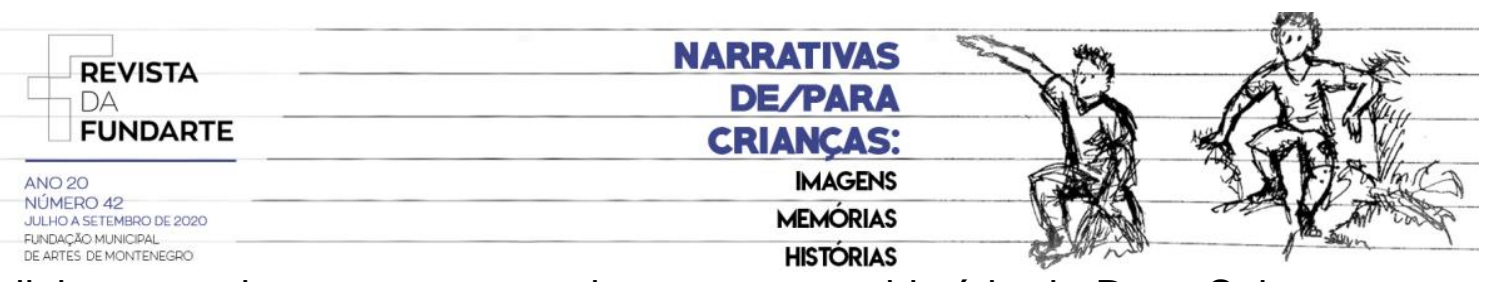

religioso, precisava contar a qualquer pessoa a história do Deus Sol, num certo dia dedicado a ele. A velha percorre a cidade inteira, sem encontrar uma só pessoa que pudesse interromper suas atividades por alguns poucos minutos para ouvi-la. Por fim, ela chega ao arrabalde mais pobre da cidade, onde vive a humilde casta dos vendedores de sal, e ali encontra uma jovem grávida, descansando à beira do caminho. Esta se dispõe a ouvir a história, mas adormece antes que a velha consiga começar a narrar. Paciente, a velha espera ao lado, até ouvir um sussurro vindo do ventre da moça: Conta pra mim! Assustada, a senhora atende ao pedido da criança ainda não nascida e conta a ela a história ritual, enquanto a jovem grávida dorme. Dias depois, nasce a criança, que era uma menina, e a partir daí o conto se desenrola em peripécias surpreendentes, nas quais se percebe aos poucos que a menina possuía grandes e misteriosos poderes. Ao final, descobre-se que tais dons haviam sido presentes do próprio Deus Sol, para a única pessoa que tinha se dignado a escutar sua história muitos anos antes, quando ainda no ventre da mãe. A última frase do conto é: "Vejam o poder que se pode ganhar ao simplesmente ouvir uma história ${ }^{3 " .}$.

No conto acima, ouvir uma história está longe de ser uma postura passiva: é decisão, é deliberação à entrega, é intenção de abertura à palavra do outro. Como podemos, diante das crianças, manifestar claramente nosso desejo de escutar o que elas têm para contar, seguindo o exemplo do bebê na barriga da mãe, que diz: Conta pra mim!? Dialogo a seguir com mais algumas respostas, encontradas por pesquisadoras brasileiras em suas buscas recentes de ouvir as histórias das crianças.

\section{Conta pra mim?}

Dispor-se a estar junto das crianças onde elas estiverem, criar um tempo para a escuta cúmplice e interessada, imaginar formas de animá-las a contar histórias, estes são desafios enfrentados de maneiras diferentes em cada situação de

\footnotetext{
3 Um reconto dessa história na íntegra está em GIRARDELLO, G: Na clareira do presente: o diálogo narrativo entre as gerações. In: MORAES, F; GOMES,L. (org.) [2012]: A arte de encantar: o contador de histórias contemporâneo e seus olhares. São Paulo, Cortez Editora, 2012.
}

GIRARDELLO, Gilka. Eu tenho uma coisa pra contar": Inspirações para a escuta das narrativas infantis. Revista da FUNDARTE. Montenegro, p.01-20, ano 20, oㅡ 42, julho/setembro de 2020.

Disponível em: http://.seer.fundarte.rs.gov.br/index.php/RevistadaFundarte/index $>30$ de setembro de 2020 


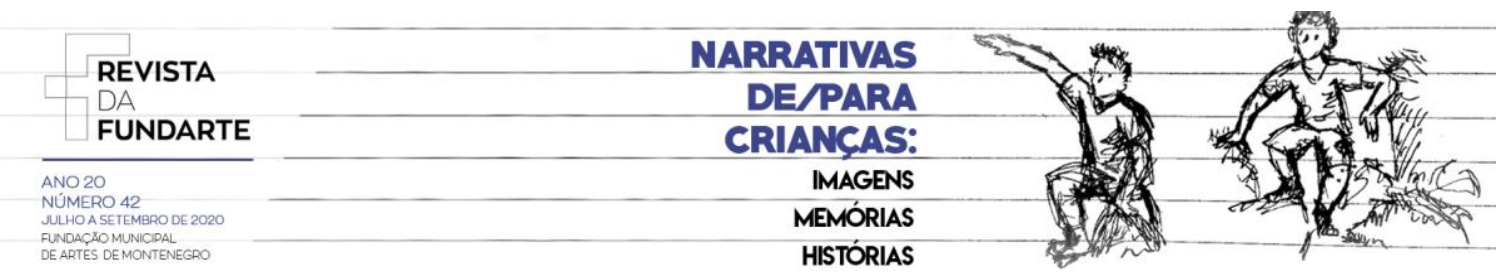

pesquisa. Nos relatos a seguir, os autores desenvolveram ou usaram a seu modo uma variedade de estratégias para lidar com tais desafios. Um exemplo é a decisão de Karin Campos (2016) de acompanhar as crianças em seu trajeto de ônibus escolar de volta para casa, em várias viagens ao longo de pequenas estradas rurais no Oeste do Paraná. Ela deixou claro para as crianças que queria aproveitar a oportunidade para ouvir mais e conhecer melhor suas histórias, e avalia como tendo sido preciosas as experiências de

\begin{abstract}
poder sentar junto com elas na kombi e no ônibus; conversar e avistar paisagens do campo; de poder conhecer um pouco da rotina das crianças; de acompanhar a descida e a subida de diferentes crianças da escola; do olhar do motorista que queria entender por que a professora se interessava em acompanhar as crianças no trajeto para casa; de visualizar a cena da mãe que esperava na beira da estrada a kombi passar para embarcar seu filho para ir à escola estudar; da cena do pai sentado na varanda tomando chimarrão avistando o filho chegar para depois almoçarem juntos; da expressão de contentamento e orgulho das crianças porque a professora os acompanhava - relato da professora da escola - e do desejo delas de que eu pudesse descer só um pouquinho para visitar sua casa e conhecer seus pais, poder conhecer o cachorro das histórias ouvidas esperando na frente da casa o menino contador de histórias chegar; de sentir - ainda que talvez uma experiência muito curta mas ainda uma experiência - como é viver no campo, com casas distantes uma das outras, mas rodeadas de paisagens bonitas; de sentir um silêncio que só é atrapalhado por barulho de pássaros ou de algum outro animal; e de poder, principalmente, conhecer e imaginar melhor como é o lugar das histórias das crianças. (CAMPOS, 2016, p. 118).
\end{abstract}

Em outros momentos desse mesmo trabalho de campo, a pesquisadora apostou na tradição cultural em que as pessoas costumam conversar e partilhar histórias enquanto fazem juntas algum trabalho manual: propôs que as crianças confeccionassem coletivamente uma colcha de retalhos, cada um com um significado especial ligado à vida delas. A aposta deu certo, pois nas muitas horas em que a turma ficava em sala, trabalhando em conjunto, pintando e costurando, muitas e muitas narrativas emergiram espontaneamente, no fluxo de uma conversa sem pressa.

Outra proposta interessante para inspirar a narrativa infantil é o trabalho de Cecília Schubsky (2018), uma professora de história do Rio de Janeiro que pediu que seus alunos, com 10 e 11 anos de idade, montassem "caixinhas de memória",

GIRARDELLO, Gilka. Eu tenho uma coisa pra contar": Inspirações para a escuta das narrativas infantis. Revista da FUNDARTE. Montenegro, p.01-20, ano 20, № 42, julho/setembro de 2020.

Disponível em: http://.seer.fundarte.rs.gov.br/index.php/RevistadaFundarte/index $>30$ de setembro de 2020 


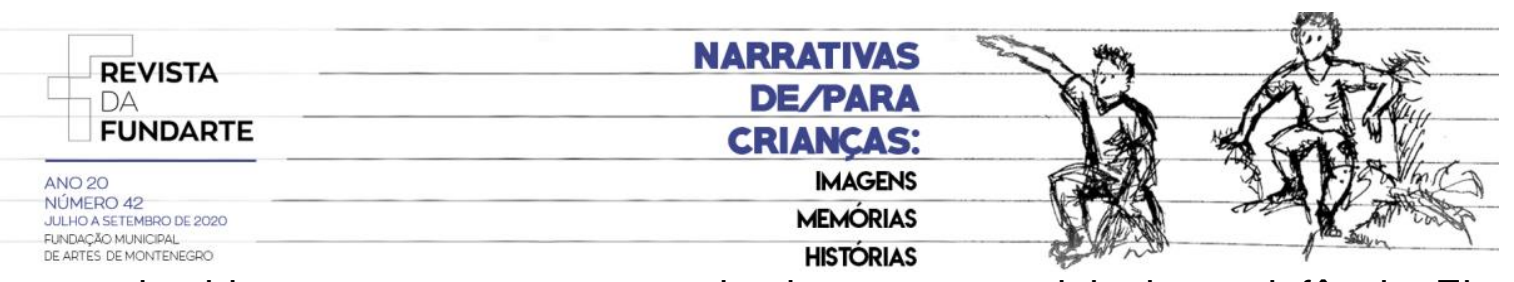

contendo objetos que representassem lembranças especiais de sua infância. Ela diz:

"eu buscava as narrativas que estavam por detrás de cada coisa que elas julgavam preciosas" (SCHUBSKY, 2018, p. 108). Os objetos serviram como apoio à fala das crianças, desencadeando os processos narrativos:

\begin{abstract}
Ao observar os objetos trazidos pelos meninos, sejam brinquedos dados por entes queridos que já se foram, mapas de lugares onde viajaram, pedras recolhidas em lugares que visitaram, entradas para shows, ingressos de espetáculos e uma infinidade de coisinhas, pude perceber que eles têm um significado especial para seus donos. Esses objetos [...] têm uma história, uma narrativa que thes acompanha. Algo que faz sentido para quem narra e passa a existir no mundo à medida que essa narrativa é escutada por outros. (SCHUBSKY, 2018, p. 76).
\end{abstract}

Outra dimensão favorável à escuta sensível é a qualidade do silêncio que se oferece para receber o contar das crianças. Afinal, já dizia Riobaldo, o narrador de Grande Sertão: Veredas: "O senhor...Me dê um silêncio. Eu vou contar." (ROSA, 1988, p. 525). Nesse sentido, é inspiradora a tese de Angela Fronckowiak (2013), no Rio Grande do Sul, sobre a escuta sensível em uma experiência de "convívio poético" com crianças. A autora discute a importância do silêncio para a escuta, ressalvando que em sua pesquisa "não era o silêncio para o outro que eu buscava, mas o silêncio para minhas certezas", para que fosse possível perceber o quanto as crianças são capazes de fazer "desde que cessem, ao menos um pouco, as adultas insistentes falas" (FRONCKOWIAK, 2013, p. 140). Isso nos sugere a importância de estabelecermos com as crianças esse silêncio pregnante, que seja espaço de inspiração, respiro e reverberação das matérias imaginativas suscitadas pelas histórias contadas. Não um silêncio decretado do alto de uma voz de autoridade, mas sim um silêncio que vá brotando de baixo, devagarinho, do chão comum entretecido pelas raízes das experiências compartilhadas aos poucos no grupo. Ou seja: não um silêncio qualquer, para que também a voz das crianças não seja uma voz qualquer.

Além de oferecer um silêncio qualificado, é preciso também que nos sintonizemos com as diferentes linguagens com que as crianças se expressam antes, durante e depois das palavras: seus gestos, ritmos e cantigas, a miríade de 


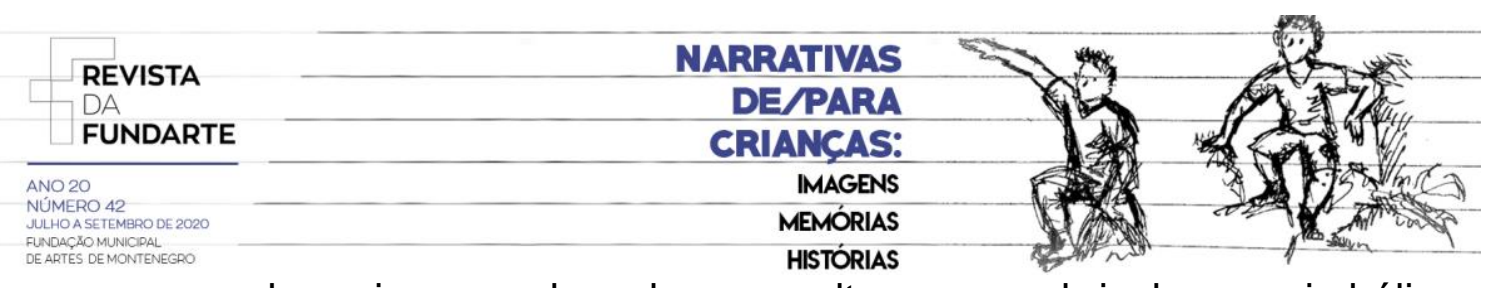

imagens que elas criam em desenhos, esculturas e na bricolagem simbólica com que reúnem e dão sentido aos diferentes objetos que encontram ao seu redor. A atenção a essas diferentes linguagens aparece em outra pesquisa brasileira recente, na qual a autora (SODRÉ, 2017) relata os diálogos com crianças entre quatro e cinco anos de idade, em São Paulo, a partir da narração oral de contos tradicionais:

\begin{abstract}
Durante a pesquisa, com frequência as crianças fizeram uso de outras linguagens, que não a oral, para se expressarem. Fosse por gestos, para imitar um cavalo trotando, movimentos de nadar, de plantar uma muda, o modo de um animal andar; ou fosse para testar a expressão facial e corporal de um dado personagem, as manifestações sempre vinham acompanhadas da fala "ele/ela fazia assim, ó!". (SODRÉ, 2017, p. 86-7).
\end{abstract}

Como diz a pesquisadora Liliane Alves da Silva, criadora de um projeto de Roda de Histórias que transformou-se em disciplina curricular no Colégio de Aplicação da Universidade Federal de Santa Catarina: "Não é possível ouvir as 'vozes' das crianças se usarmos apenas as linguagens dos adultos. É necessário e urgente aprendermos suas cem linguagens e não lhes roubar noventa e nove" (Silva, 2018, p. 107). Ela faz aí referência ao conhecido poema do educador italiano Lóris Malaguzzi, que diz que "as crianças têm cem modos pensar/ de jogar e de falar /(...) mas roubaram-Ihes noventa e nove. / A escola e a cultura/ the separam a cabeça do corpo./ Dizem-Ihe: de pensar sem as mãos/ de fazer sem a cabeça/ de escutar e de não falar/ de compreender sem alegrias/ de amar e maravilhar-se só na Páscoa e no Natal" (EDWARDS; GANDINI; FORMAN, 2016, s/p). Nesse sentido, a escuta é um abertura mais ampla e orgânica aos sentidos possíveis do que a criança enuncia em suas múltiplas formas de dizer: com o olhar, o tom de voz, a postura física, o que as mãos desenham no ar e no papel, o que modelam com os materiais do mundo. Nesse sentido, enfim, escutar é ler o mundo ao ler o outro - é ler o mundo do outro.

Também é importante lembrar que o jogo-do-contar, o lúdico pingue-pongue dialógico pelo qual a criança aprende a narrar na primeira infância, lá nos primórdios de sua aventura linguageira, permanece vivo e necessário ao longo dos anos. Assim, o narrar segue precisando desse apoio fático em que a escuta do outro se 


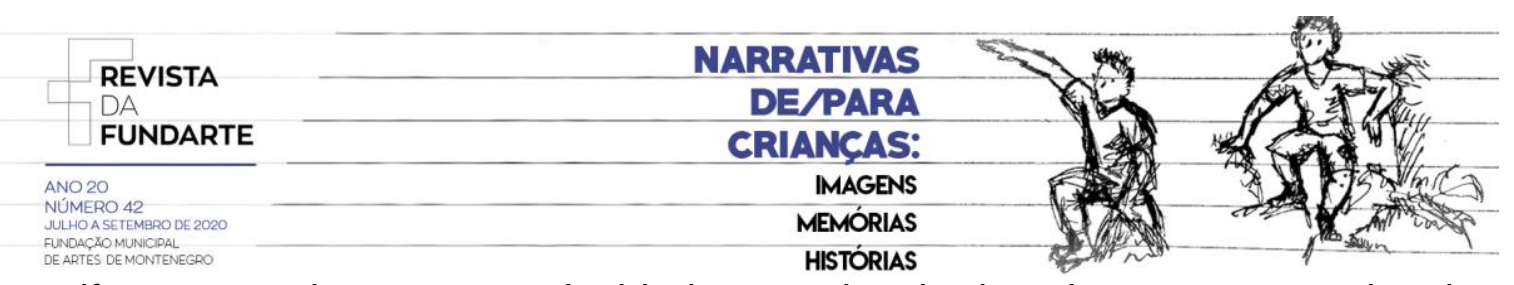

manifesta em palavras, na curiosidade e no desejo de saber o que vem depois e de entender melhor o que veio antes. Esse movimento é encontrado nos registros das pesquisas recentes, como neste diálogo ocorrido em uma turma de crianças de 5 e 6 anos, em uma roda de recontos em Brasília:

Pesquisadora: Eu não conheço a história da Casa Monstro. O quê que acontece? Como é que começa?

[Criança]: Sei que bate, que bate na porta...Tem um quadro que tem uma mulher que fica assim, ó. (Vira os olhos para a direita e para a esquerda).

Pesquisadora: Hum...Tô vendo.

[Criança]: Aí ela falou: "Enta, seu dotô."

Pesquisadora: E aí? (...) (Vieira; Coelho, 2018, p. 22).

Percebemos aí como a curiosidade da pesquisadora adulta, expressa com naturalidade, serve de apoio à fala da criança, que vai se constituindo aos poucos. Escutar uma criança é também ir soltando linha para que sua voz narrativa, como uma colorida pipa de papel, possa voar livre e ao mesmo tempo em segurança.

\section{E daí...}

Para escutar bem as histórias que as crianças nos contam, enfim, é preciso cultivar em nós uma escuta solidária e compreensiva, do tipo que caracteriza um diálogo. Elas precisam sentir em nós uma atenção verdadeiramente respeitosa pela complexidade do que expressam, valendo-se dos recursos de linguagem de que dispõem. As crianças merecem de nós uma escuta genuinamente curiosa, aberta às surpresas e aos aprendizados que os enredos, roteiros, imagens e palavras presentes em suas narrativas possam despertar em nós. Como vimos em exemplos extraídos de pesquisas brasileiras recentes, é imprescindível um esforço de invenção pedagógica para criar estratégias que tornem mais fácil para as crianças encontrar suas vozes quando estas estão silenciadas, de modo a que, contando em fato e ficção o que lhes aconteceu, possam ter certeza do quanto a vida de cada uma delas é única e preciosa.

Mas escutar as histórias das crianças não é vital apenas para que elas se constituam como sujeitos mais inteiros. Dizia Walter Benjamin que as imagens vistas pela primeira vez exercem grande poder sobre a imaginação. Se é assim, e 


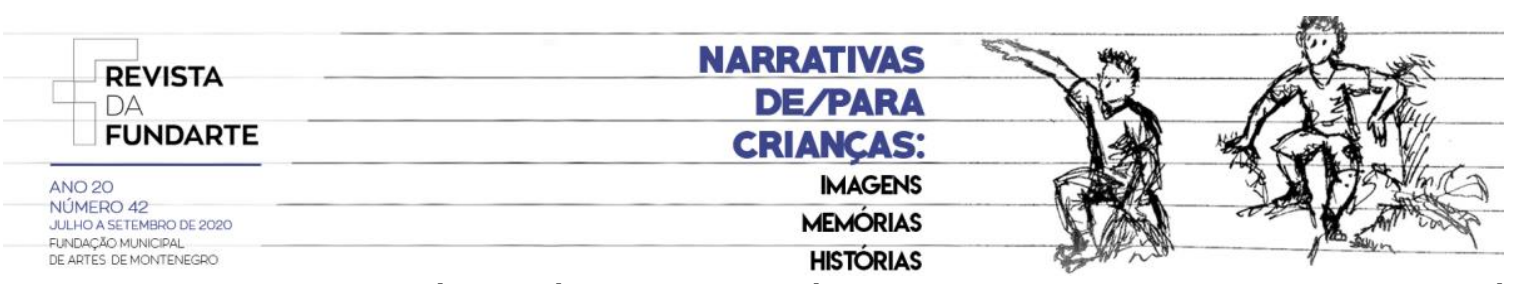

pensamos que o seja, é possível que também as imagens suscitadas pelas histórias das crianças, em sua originalidade e frescor, tenham algum especial poder sobre a nossa própria imaginação de adultos. E, diante dos enormes desafios sociais, econômicos e culturais da atualidade, que tanto nos exigem imaginar novas possibilidades de um mundo melhor, não parece prudente deixar de lado ou tratar como coisa banal a incessante fonte de novidade que sussurra nas palavras das crianças nas histórias que elas nos contam.

\section{Referências:}

APPLEBEE, A. The Child's Concept of Story. The University of Chicago Press, 1978.

BAKHTIN, M. Speech Genres and Other Late Essays. In: HOLQUIST, M.; EMERSON, C. Speech Genres and Other Late Essays. Austin: University of Texas Press, 1986.

BERMAN, R. A. Narrative Competence and Storytelling Performance: How Children Tell Stories in Different Contexts. Journal of Narrative and Life History. 5,(4). Lawrence Erlbaum Associates, 1985.

BORMANN, E. G. Symbolic Convergence Theory. Storytelling in Mass Culture and Everyday Life. The Journal of Communications. Philadelphia: University of Pennsylvania, 1986.

BRUNER, J. Realidade mental, mundos possíveis. Porto Alegre: Artmed, 1997.

CAMPOS, K.C. Nossas vidas contam histórias: crianças narradoras. Tese de Doutorado em Educação. Florianópolis: Universidade Federal de Santa Catarina, 2016.

CORSARO, W. Sociologia da Infância. Porto Alegre: Artmed, 2011.

EDWARDS, C.; GANDINI, L.; FORMAN, G. As cem linguagens da criança: a abordagem de Reggio Emilia na educação da primeira infância. Porto Alegre, Artmed, 1999.

FERNANDES, F. Folclore e Mudança Social na Cidade de São Paulo. Petrópolis: Vozes, 1979.

GIRARDELLO, Gilka. Eu tenho uma coisa pra contar": Inspirações para a escuta das narrativas infantis. Revista da FUNDARTE. Montenegro, p.01-20, ano 20, no 42, julho/setembro de 2020.

Disponível em: http://.seer.fundarte.rs.gov.br/index.php/RevistadaFundarte/index> 30 de setembro de 2020 


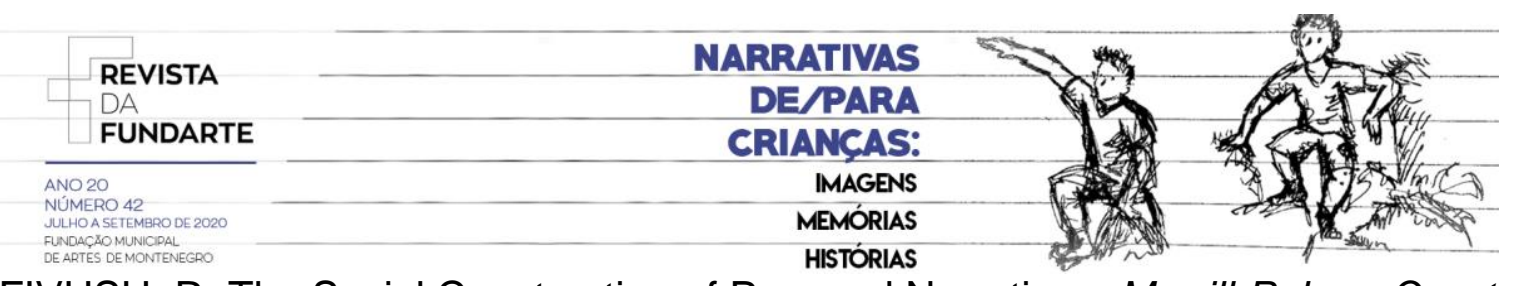

FIVUSH, R. The Social Construction of Personal Narratives. Merrill-Palmer Quarterly, vol.31(1), 1991.

FRONCKOWIAK, A. C. Com a palavra a palavra: criança e adultos em convívio poético. Tese de Doutorado em Educação. Porto Alegre: Universidade Federal do Rio Grande do Sul, 2013.

GERSIE, A. Finding the healing tale. Storytelling. Vol.2, n. 3, 1990.

GREENE, M. Releasing the imagination: essays on education, the arts and social change. San Francisco: Jossey-Bass, 1995.

HARTMANN, L. Equilibristas, viajantes, princesas e poetas: performances orais e escritas de crianças narradoras. Boitatá (Revista do GT de Literatura Oral e Popular da ANPOLL). Londrina, n.20, jul-dez 2015.

INVERNIZZI, M. A.; ABOUZEID, M.P. "One Story Map Does Not Fit All: A CrossCultural Analysis of Children's Written Story Retellings". Journal of Narrative and Life History, 5(1). Lawrence Erlbaum Associates, 1995.

LYOTARD, J.F. O Inumano: considerações sobre o tempo. Trad. Seabra, A.C.; Alexandre, E. 1a. ed. Lisboa: Estampa, 1990.

KEARNEY, R. The Wake of Imagination: Toward a postmodern culture. Minneapolis: Univ. of Minnesota Press, 1988.

MACHADO, R. No tempo em que não havia tempo. In: GIRARDELLO, G. (org.): Baús e Chaves da Narração de Histórias. Florianópolis: SESC/SC, 2004.

MACINTYRE, A. After Virtue: a study in moral theory. Indiana: University of Notre Dame, 1981.

MILLER, P.; MEHLER, R. A. The Power of Personal Storytelling in Families and Kindergartens. In: DYSON, A.; GENISHI, C. (orgs.): The Need for Story: Cultural Diversity in Classroom and Community. Teachers College. Nova York: Columbia University, 1994.

PERROTTI, E. A Criança e a Produção Cultural. In: ZILBERMAN, R. (org.) $A$ Produção Cultural para a Criança. Porto Alegre: Mercado Aberto, 1990.

RICOEUR, P. Tempo e Narrativa. (vols. I e II). Trad. M. Appenzeller. Campinas: Papirus, 1995.

ROSA, J. G. Grande Sertão: Veredas. Rio de Janeiro: Nova Fronteira, 1988.

GIRARDELLO, Gilka. Eu tenho uma coisa pra contar": Inspirações para a escuta das narrativas infantis. Revista da FUNDARTE. Montenegro, p.01-20, ano 20, № 42, julho/setembro de 2020.

Disponível em: http://.seer.fundarte.rs.gov.br/index.php/RevistadaFundarte/index $>30$ de setembro de 2020 


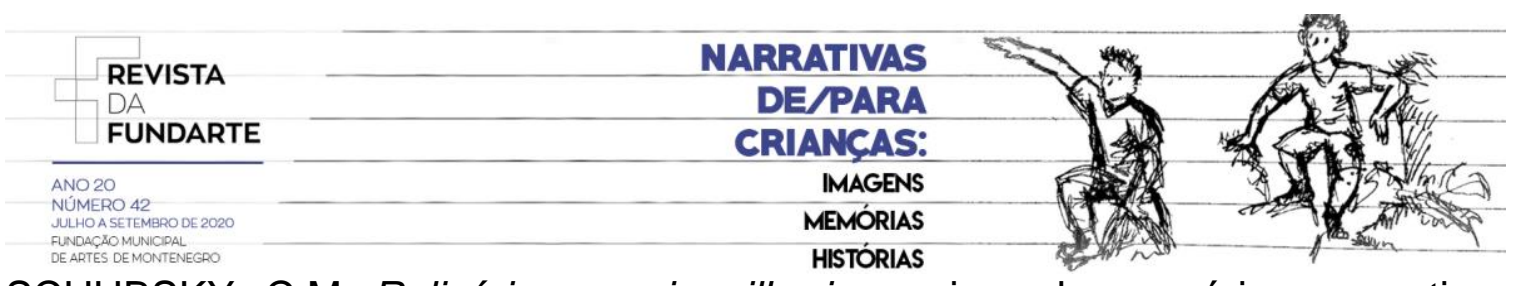

SCHUBSKY, C.M. Relicários e quinquilharias: caixas de memória e narrativas de crianças. Tese de Doutorado em Educação. Universidade do Estado do Rio de Janeiro, 2018.

SILVA, J. P.; BARBOSA, S. N.F.; KRAMER, S. Questões teórico-metodológicas da pesquisa com crianças. In: CRUZ, S. H.. A criança fala: a escuta de crianças em pesquisas. São Paulo: Cortez Editora, 2008.

SILVA, L.A.: A roda de histórias: pelo direito de viver a infância no Colégio de Aplicação - UFSC. Dissertação de Mestrado em Educação. Universidade do Estado de Santa Catarina, 2018.

SODRÉ, L. Contação de histórias e dialogia na educação infantil: uma experiência educativa. Dissertação de mestrado em Educação. São Paulo: Universidade de São Paulo, 2017.

SUTTON-SMITH, B. The Folkstories of Children. Philadelphia: University of Pennsylvania Press, 1981.

STERN, D. Crib Monologues from a Psychoanalytic Perspective. In: NELSON, K. (org.), Narratives from the Crib. Cambridge: Harvard University Press, 1989

TURNER, Victor. Social Dramas and Stories about Them. In: MITCHELL, W. J. T. (org.) On Narrative. Chicago: University of Chicago Press, 1981.

VIEIRA, D. C. S. da C.; COELHO, C.M.M. Reconto oral na interface dos processos psicológicos: emoção, memória e imaginação. In: SILVA, K.O et al: Infâncias, histórias e emoções: processos imaginativos e narrativas de crianças. Curitiba: Editora CRV, 2018.

VIGOTSKI, L.S. Imaginação e criação na infância. Trad. Z. Prestes. 1a.ed. São Paulo: Editora Ática, 2010.

GIRARDELLO, Gilka. Eu tenho uma coisa pra contar": Inspirações para a escuta das narrativas infantis. Revista da FUNDARTE. Montenegro, p.01-20, ano 20, № 42, julho/setembro de 2020.

Disponível em: http://.seer.fundarte.rs.gov.br/index.php/RevistadaFundarte/index> 30 de setembro de 2020 